\title{
Global Economic Disruption in Indonesian Company
}

ABSTRACT: Transforming business and human resources is the key for companies in Indonesia to survive in the midst of global economic un-certainty is by. Innovative transformation must depend on Good Corporate Governance. It serves as an operational foundation and is a trust for stakeholders.

\section{INTRODUCTION}

Throughout 2018, various efforts have been made to improve business rankings in Indonesia. However, these efforts are still constrained by exports and imports which have consistently tended to decline since 2015. In 2018, according to data from the World Bank Report on the ease of doing business, Indonesia is in 73rd position out of 190 countries, down one point from the previous one. in 72 nd position. It is hoped that this decline will not have a significant impact on investment, both domestically and internationally.

Global financial uncertainty tends to remain high, coupled with the global economic conditions in 2018 which tended to be sluggish and unbalanced. although the United States economy is growing strongly, inflation remains high so that the Fed tends to choose to raise the benchmark interest rate. The economies of China and Europe are also expected to grow slowly. due to deteriorating trade relations, world trade volume is also expected to be low.

Until 2020, business people in Indonesia are required to innovate and diversify in order to survive in the market. This competition makes company leaders make many changes continuously with the aim of supporting the company's vision and mission, including optimizing strategies for the maximum profit.

In fact, the results show that there are still many companies in Indonesia that don't know what to do. In the face of global economic disruption, many companies are trying to change management systems to modern ones, with the hope that the company will be sustainable and adaptive in keeping up with the times.

Economic and business developments have experienced rapid development from 2016 to 2018. Companies are often faced with business uncertainties, including advances in digital technology, changes in socio-political conditions, and the emergence of new markets.

Company management needs to build a governance system and mechanism to realize a sustainable company competitiveness, which aims to create beneficial ethical added value. The implementation of quality Good Corporate Governance (GCG) enables the creation of added value for stakeholders, and in turn will create sustainable business success. GCG practices and 
value added creation are expectedto meet three dimensions: compliance, conformance, and performance.

Companies also need a clear framework so that the direction of the organization becomes clear and measurable, and the execution of the strategies becomes appropriate and sustainable, given that efforts to build organizational capabilities are basically describing the current state of the organization and formulating the future according to the visions and missions that have been set together.

\section{RESEARCH METHODS}

Research examines the phenomena and methods used in research and then interprets the findings. The objective of the interpretive approach is to analyze the reality of global economic uncertainty and fluctuations in the exchange rate of the Rupiah (Indonesian Rupiah) against the US Dollar and their effects on corporate life in Indonesia.

Researchers try to explore how business people perceive economic disruption and how business people save and shape their own reality so that they become accustomed to these economic disruptions by using primary data and secondary data. The researcher then interpreted these findings based on the perspectives used by business people in Indonesia.

\section{RESULTS AND DISCUSSIONS}

There has been an increase in the population of large and medium industries from 2014 to 2017, previously, in 2014 there were 25,094 business entities to 30,992 business entities in 2017. The small industry sector also experienced an increase. Currently, the industrial sector which is closely related to the use of high technology tends to be aggressive in recruiting new workers. Digital trends do create many job opportunities, but most of them are informal and do not have official legal status. So, fast-moving digital technology actually demands changes in skills, while the skills that workers have today may not be needed in the future, so new competencies are needed. When the company carries out a new strategy, one of the problems that often arises is the readiness of the organization in terms of aligning the strategy that will be carried out with the business processes carried out within the organization, organizational structure, human resource competence, and culture. For this reason, a self-assessment is needed so that the direction and alignment of the company adjustment process.

There is a popular saying in society "nothing is permanent unless change". It is indeed proven that the trends of globalization, digitization and trade wars have made the world experience volatility, uncertainty, complexity and ambiguity (VUCA). Business and human 
resource transformation are important to face challenges from external and internal factors, as has been implemented by PT. BNI, Tbk. And PT. Hartono Plantation Indonesia (HPI-Argo). Digital transformation from PT. BNI, Tbk is a transformation to mobile banking, digital lending, mobile remittance, chat banking and QR Code-based payment applications, on the other hand, HPI-Agro makes changes to annual crops into seasonal crops, develops projects into established organizations, investment modes become operational mode, administration becomes strategic manager, ad-hoc becomes planning-based, traditional organization becomes modern, plantation becomes agricultural industry, offers to demand management and followers become innovators.

The transformation process is related to innovative ideas and must not violate business ethics and GCG principles. Implementing GCG is not only an obligation regulation, but as part of company tools and guidelines that can be used as an operational basis. The implementation of a sustainable GCG system encourages companies to create new values in the aspects of products, operations and services that improve company performance. So, GCG increases stakeholder trust and indirectly increases investment by attracting investors in its shares.

The effectiveness of an organizational structure is greatly influenced by the quality of the leadership and the management system applied to create superior products and services in accordance with market expectations. Employees sometimes feel that they have no ties to the company (Dessler 2005), so that this can become a problem and disappoint consumers, so employee engagement is needed.

Employee involvement is the main key for a company that is currently experiencing global economic disruption. Employee engagement provides access to management to further improve employee conditions through efforts to build high commitment and better accommodate aspects of employee satisfaction with the company. in the end, the process can be implemented into daily operational activities. Employee involvement is expected to foster enthusiasm, motivation, and proactive encouragement for employees to provide optimal efforts in every business activity.

\section{CONCLUSION}

The conclusion, in the face of a global economic disruption full of volatility, uncertainty, complexity and ambiguity (VUCA), companies need to transform and increase their competitive advantage, starting from a leader who has a positive aura and becomes a role model for all employees. thus, the company can move in the same direction and increase 
company value, market value, cultural value, information disclosure, the effectiveness of the audit system, risk control and profit maximization.

\section{REFERENCES}

Tayibnapis, A. Z., Wuryaningsih, L. E., Gora, R. (2019). Companies in Indonesia in the Vortex of Global Economic Disruption. Advances in Social Science, Education and Humanities Research, Vol.308. 